\title{
Insulin resistance and chronic hepatitis $\mathbf{C}$ in non-diabetic patients
}

Viroj Wiwanitkit ${ }^{1}$

$\mathrm{T}$ The recent publication on Insulin resistance and chronic hepatitis $\mathrm{C}$ in non-diabetic patients was very interesting (1). Souza and cols. concluded that "Insulin resistance is often present in patients with chronic hepatitis $\mathrm{C}$, and this parameter is associated with more advanced HCV-related hepatic fibrosis (1)." The finding in this study is concordant with the recent report by Itoh and cols. (2). It is believed that direct damage caused by the virus with proinflammatory cytokines will interfere with normal insulin signaling, and this further disturbs glucose metabolism (3). However, some issues on the present study (1) should be mentioned. First, the protocol in the present study cannot exclude the interference of other possible confounding diseases in the patients (such as HIV and other uncommon hepatitis virus infection). Second, this is only an observational study, hence, it is not reasonable to draw conclusions on any association (which would require an analytical study).

Disclosure: no potential conflict of interest relevant to this article was reported.

\section{REFERENCES}

1. Souza AF, Pace FH, Chebli JM, Ferreira LE. Insulin resistance in non-diabetic patients with chronic hepatitis C: what does it mean?. Arq Bras Endocrinol Metab. 2011;55(6):412-8.

2. Itoh Y, Nishimura T, Yamaguchi K, Yokomizo C, Fujii H, Minami M, et al. Hepatic steatosis in chronic hepatitis $C$ patients infected with genotype 2 is associated with insulin resistance, hepatic fibrosis and affects cumulative positivity of serum hepatitis $C$ virus RNA in peginterferon and ribavirin combination therapy. Hepatol Res. 2011;41(12):1145-52. doi: 10.1111/j.1872-034X.2011.00886.x. Epub 2011 Sep 26.

3. Gutiérrez-GrobeY, Ponciano-Rodríguez G, Méndez-Sánchez N. Viral hepatitis infection and insulin resistance: a review of the pathophysiological mechanisms. Salud Publica Mex. 2011;53 Suppl 1:S46-51.

${ }^{1}$ Wiwanitkit House, Bangkhae, Bangkok Thailand 10160
Correspondence to: Viroj Wiwanitkit

Wiwanitkit House, Bangkhae, Bangkok Thailand 10160 wviroj@yahoo.com

Received on 17/Oct/2011 Accepted on 17/Nov/2011 